\title{
Outcome after protected full weightbearing treatment in an orthopedic device in diabetic neuropathic arthropathy (Charcot arthropathy): a comparison of unilaterally and bilaterally affected patients
}

\author{
Niklas Renner ${ }^{1 *}$, Stephan Hermann Wirth², Georg Osterhoff ${ }^{3}$, Thomas Böni ${ }^{2}$ and Martin Berli
}

\begin{abstract}
Background: Charcot neuropathic arthropathy (CN) is a chronic, progressive, destructive, non-infectious process that most frequently affects the bone architecture of the foot in patients with sensory neuropathy. We evaluated the outcome of protected weightbearing treatment of $\mathrm{CN}$ in unilaterally and bilaterally affected patients and secondarily compared outcomes in protected versus unprotected weightbearing treatment.
\end{abstract}

Methods: Patient records and radiographs from 2002 to 2012 were retrospectively analyzed. Patients with Type 1 or Type 2 diabetes with peripheral neuropathy were included. Exclusion criteria included immunosuppressive or osteoactive medication and the presence of bone tumors. Ninety patients $(101 \mathrm{ft})$, mean age $60.7 \pm 10.6$ years at first diagnosis of $\mathrm{CN}$, were identified. Protected weightbearing treatment was achieved by total contact cast or custom-made orthosis. Ulcer, infection, CN recurrence, and amputation rates were recorded. Mean follow-up was 48 (range 1-208) months.

Results: Per the Eichenholtz classification, $9 \mathrm{ft}$ were prodromal, 61 in stage 1 (development), 21 in stage 2 (coalescence) and 10 in stage 3 (reconstruction). Duration of protected weightbearing was $20 \pm 21$ weeks and $22 \pm$ 29 weeks in patients with unilateral and bilateral $C N$, respectively. In bilaterally affected patients, new ulcers developed in 9/22 (41\%) feet. In unilaterally affected patients, new ulcers developed in 5/66 (8\%) protected weightbearing feet and $4 / 13$ (31\%) unprotected, full weightbearing feet $(p=0.036)$. The ulceration rate was significantly higher in bilaterally versus unilaterally affected patients with a protected weightbearing regimen ( $p=0$. 004). Soft tissue infection occurred in 1/13 (8\%) unprotected weightbearing feet and 1/66 (2\%) protected weightbearing feet in unilaterally affected patients, and in $1 / 22$ (4\%) protected weightbearing feet of bilaterally affected patients. Recurrence and amputation rates were similar across treatment modalities.

Conclusions: Bilateral $\mathrm{CN}$ results in significantly more ulcers than unilateral $\mathrm{CN}$ and leads to slightly higher soft tissue infections. Protected weightbearing in an orthopedic device can reduce the risk for complications in acute $\mathrm{CN}$ of the foot and ankle.

Keywords: Bilateral, Charcot, Diabetic neuropathic arthropathy, Neuroosteoarthroapthy, Infection, Protected weightbearing, Total contact cast, Ulcer

\footnotetext{
*Correspondence: niklas.renner@okl-ag.ch

'Orthopädische Klinik Luzern AG, Hirslanden Klinik St.Anna, Luzern,

Switzerland

Full list of author information is available at the end of the article
} 


\section{Background}

Charcot neuropathic arthropathy $(\mathrm{CN})$ is a chronic, progressive, destructive, non-infectious process leading to progressive degeneration of a weightbearing joint. It most frequently affects the osseous alignment of the foot and joint alignment in people with sensory neuropathy [1]. The disease was first described in 1868 by Jean-Martin Charcot in the context of tabes dorsalis $[2,3]$. Today, diabetes mellitus is the most common cause of peripheral neuropathy and is therefore often associated with the development of $\mathrm{CN}$. From 0.08 to $7.5 \%$ of diabetic patients are diagnosed with $\mathrm{CN}$ [4]. With the worldwide increase in the prevalence of diabetes, diagnosis and treatment of $\mathrm{CN}$ is becoming more important [5].

The main characteristics of $\mathrm{CN}$ are atraumatic swelling with redness and warmth, followed by deformation of the foot. Often this occurs in only one foot [6]. The exact pathogenesis of $\mathrm{CN}$ is still unclear. However, there are several predisposing factors, such as the retention of vasodilitatory reflexes of the affected foot, upregulation of calcitonin gene related peptide and reduction in bone mineral density [7-9]. Once the disease has been triggered, it progresses to an uncontrolled inflammation. The loss of pain sensation and proprioception combined with repetitive mechanical trauma to the foot leads to fractures and joint dislocations [10-12]. Once a bone has fractured, proinflammatory cytokines such as tumor necrosis factor- $\alpha$ (TNF- $\alpha$ ) and interleukin-1 $\beta$ (IL-1 $\beta$ ) are released, resulting in increased expression of receptor activator of nuclear factor$\mathrm{kB}$ ligand (RANKL), synthesis of the nuclear transcription factor NF-kB, and maturation of osteoclasts [8, 13]. Bone resorption leads to bony destruction, weakening of ligaments, and consequent joint destruction secondary to contributory trauma [14]. Hyperemia through an autonomically stimulated vascular reflex causes additional periarticular osteopenia [12].

The pathogenesis of $\mathrm{CN}$ in the foot differs between patients with Type 1 and Type 2 diabetes. Petrova et al found a younger age at onset, a generalized reduction in bone mineral density, and more severe peripheral neuropathy in patients with Type 1 diabetes compared to those with Type 2 diabetes [15].

The progression of $\mathrm{CN}$ follows the stages originally described by Eichenholtz [16]. A prodromal inflammation stage with normal radiographs (Stage 0) is followed by increasing osseous destruction with radiographic evidence of osseous fragmentation and joint dislocation (Stage 1, "fragmentation") and subsequent coalescence of fragments and absorption of fine bone debris (Stage 2, "coalescence"). Finally, chronic deformity of the foot with consolidation and remodeling of fracture fragments is observed (Stage 3, "reconstruction").

Charcot neuropathic arthropathy severely reduces the overall quality of life and dramatically increases the morbidity and mortality of patients [17, 18]. Evidencebased guidelines for the treatment of acute $\mathrm{CN}$ have yet to be established. Non-operative treatment to achieve a plantigrade, stable foot and prevent recurrent ulceration is regarded as the primary treatment for acute $\mathrm{CN}$ feet $[19,20]$. Operative treatment is often reserved for late complications, such as deep wound infection or osteomyelitis [20, 21]. Nevertheless, early reconstructive surgery in patients with an unstable foot with manifest joint subluxation or radiographic non-plantigrade foot position may provide timely restoration of the plantigrade foot [22]. In particular, unstable deformities in obese patients are sometimes difficult to brace, and these patients might benefit from primary corrective arthrodesis $[23,24]$. However, despite satisfactory results, complication rates following surgery are reported to range from $10 \%$ to more than $30 \%[24,25]$.

The aim of the present study was to compare the outcome of non-operative treatment in patients diagnosed with unilateral versus bilateral $\mathrm{CN}$. Additionally, we compared outcomes of protected versus unprotected weightbearing non-operative treatment and made recommendations for non-operative therapeutic options.

\section{Methods \\ Data acquisition}

We conducted a retrospective cohort chart review study at a specialized centre for multidisciplinary treatment of foot ulcerations and deformities over an eleven-year period (2002-2012). We conducted a comprehensive search strategy of our institutional database using the keywords "Charcot" or "Neuroosteoarthropathy". Patients older than 18 years with confirmation of $\mathrm{CN}$ by magnetic resonance imaging (MRI) (i.e., soft tissue edema, joint effusion, and/or subchondral bone marrow edema of involved joints, characterized by low signal intensity on T1-weighted images and high signal intensity on T2-weighted images) at the beginning of treatment were included in the study. Only patients with a diagnosis of Type 1 or Type 2 diabetes with peripheral neuropathy recorded in their charts were included. Individuals treated with immunosuppressive or osteoactive medication (i.e., bisphosphonates) and patients with osteodestructive bone pathologies, i.e. bone tumors, were excluded. Patients with diagnosed osteomyelitis or idiopathic osteoarthropathy were also excluded.

The following data were collected from the patient records: age, gender, affected limb, duration of diabetes, time period of protected weightbearing, date of first diagnosis of $\mathrm{CN}$, recurrence of $\mathrm{CN}$ (i.e. new foot deformity and/or non-infectious swelling and redness), appearance of ulcer or infection, type of definitive treatment and surgical intervention for treatment of wounds and infections. This study was carried out in accordance with our institutional 
ethics committee's terms of reference. Written informed consent allowing retrospective data analysis was received from all patients enrolled in the study.

\section{Patients}

A total of 90 patients were identified (age 60.7 \pm 10.6 years at first diagnosis of $\mathrm{CN}$ ), with 101 affected feet. Eleven patients (12\%) had bilateral CN.

The study included 22 (24\%) women and 68 (76\%) men, with 28 and 73 affected feet, respectively. Of the 79 unilaterally affected patients, 39 were left feet and 40 were right feet (Table 1).

$\mathrm{CN}$ was staged according to the Eichenholtz classification [16] by the treating clinician. In unilaterally affected patients, $6(8 \%)$ were treated in the prodromal period (stage 0), 49 (61\%) demonstrated acute stage $1 \mathrm{CN}$ at the time of first diagnosis, $16(21 \%)$ were diagnosed and

Table 1 Baseline patient characteristics

\begin{tabular}{|c|c|}
\hline Characteristic & Number \\
\hline \multicolumn{2}{|l|}{ Patients $(n=90)$} \\
\hline Age at initial diagnosis (years), mean \pm SD & $60.7 \pm 10.6$ \\
\hline Follow up period (years), mean \pm SD & $3.7 \pm 3.8$ \\
\hline Gender, female/male, $\mathrm{n}$ & $22 / 68$ \\
\hline $\begin{array}{l}\text { Bilateral patients }(n=11) \text { gender: } \\
\text { female/male, } \mathrm{n}\end{array}$ & $6 / 5$ \\
\hline \multicolumn{2}{|l|}{ Comorbidity, $n(\%)^{a}$} \\
\hline - Diabetes & $90(100)$ \\
\hline - Peripheral vascular disease ${ }^{b}$ & $14(16)$ \\
\hline - Obesity (BMI > 25 kg/m2) & $12(13)$ \\
\hline \multicolumn{2}{|l|}{ Affected feet $(n=101)$} \\
\hline Female/male, $\mathrm{n}$ & $28 / 73$ \\
\hline $\begin{array}{l}\text { Left/right (in unilaterally affected } \\
\text { patients, } n=79 \text { ), } n\end{array}$ & $39 / 40$ \\
\hline \multicolumn{2}{|l|}{ Location of $\mathrm{CN}^{\mathrm{c}}(n=101 \mathrm{ft})$} \\
\hline $\begin{array}{l}\text { Zone } 1 \text { (distal and proximal interphalangeal } \\
\text { joints, metatarsophalangeal joints) }\end{array}$ & 10 unilateral, 2 bilateral \\
\hline Zone 2 (tarsometatarsal joints (Lisfranc) & 25 unilateral, 10 bilateral \\
\hline $\begin{array}{l}\text { Zone } 3 \text { (naviculo-cuneiform joints, } \\
\text { talonavicular joint; cacaneocuboid joint) }\end{array}$ & 8 unilateral, 5 bilateral \\
\hline Zone 4 (ankle joint, subtalar joint) & 3 unilateral, 0 bilateral \\
\hline Zone 5 (calcaneus) & 2 unilateral, 0 bilateral \\
\hline Zones $1+2$ & 6 unilateral, 0 bilateral \\
\hline Zones $2+3$ & 1 unilateral, 0 bilateral \\
\hline Zones $2+4$ & 19 unilateral, 5 bilateral \\
\hline Zones $3+4$ & 3 unilateral, 0 bilateral \\
\hline Zones $4+5$ & 2 unilateral, 0 bilateral \\
\hline
\end{tabular}

$B M I$ body mass index

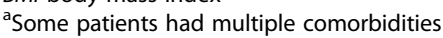

${ }^{b}$ Confirmed with ankle-brachial index $(\mathrm{ABI})<0.9$

'Based on Sanders and Frykberg Anatomic Classification [26] treated in the coalescence stage 2, and $8(10 \%)$ were treated for chronic stage $3 \mathrm{CN}$ [16]. In bilaterally affected patients, $3 \mathrm{ft}(14 \%)$ were treated in the prodromal period, $12 \mathrm{ft}(54 \%)$ in the acute stage, $5 \mathrm{ft}(23 \%)$ were diagnosed in stage 2, and $2 \mathrm{ft}(9 \%)$ were diagnosed in stage 3. Based on Sanders and Frykberg Anatomic Classification [26], CN was located in the forefoot in $20 \%$ of feet, the midfoot in $67 \%$ of feet, and the hindfoot in $13 \%$ of feet in unilaterally affected patients (Table 1). In bilaterally affected patients, $\mathrm{CN}$ was located in the forefoot in $9 \%$ of feet and the midfoot in $91 \%$ of feet.

\section{Non-operative treatment modalities: protected weightbearing}

Sixty-six unilaterally affected patients were treated with protected weightbearing. Of these, $57 \mathrm{ft}(87 \%)$ were initially supplied with a total contact cast (TCC), consisting of a properly cushioned, custom-made rigid fiberglass boot (Fig. 1). Patients were allowed to bear weight as tolerated with the aid of two crutches, if needed. Immobilization consisting of bed rest or limitation in walking activity was not required. The TCC was followed by a removable TCC (rTCC) in $20 \mathrm{ft}(30 \%)$ or a custommade orthosis in $11 \mathrm{ft}(17 \%)$ when symptoms like redness and warmth had decreased sufficiently based on visual inspection and palpation and no ulcer or infection

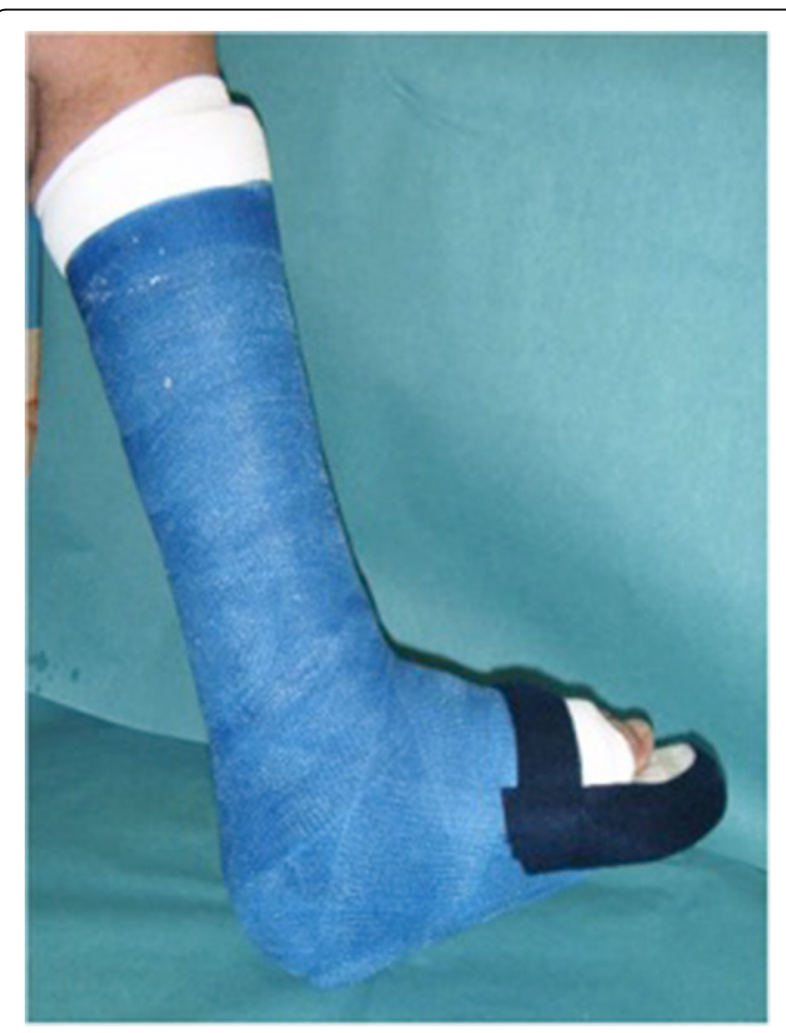

Fig. 1 Example of a total contact cast (TCC), consisting of a properly cushioned, custom-made, rigid, fiberglass boot 
was detected (Table 2, Fig. 2). Cast changes were made at least every second week by a professionally trained technician. Patients were seen every three to four weeks in the outpatient clinic of our institution for follow-up.

Eleven patients were affected bilaterally. Nine patients received the same initial treatment on both feet: 4 received TCCs, 3 received cast shoes, and 2 received orthotics (Table 3). The remaining two patients had different stages of $\mathrm{CN}$ in each foot: one patient was treated with a TCC on one foot and a cast shoe on the other; the other patient was treated with an orthotic on one foot and a cast shoe on the other. In the $9 \mathrm{ft}$ that were supplied with a TCC, this was followed by a rTCC in $5 \mathrm{ft}$ and a rigid ankle-foot orthosis (AFO) in $1 \mathrm{ft}$. Some patients were treated with a cast shoe containing a custom-made insole because of a lack of compliance and difficulty with conducting activities of daily living with two casts.

A rigid AFO (Fig. 3) was used as initial treatment in 6 (9\%) unilaterally affected patients and $5 \mathrm{ft}$ of bilaterally affected patients. It was only used in cases of unstable foot alignment, or if the patient was unable to come to the hospital for follow-up.

In patients initially treated with protected weightbearing, definitive treatment was initiated when bony consolidation was observed. In cases of minor deformity, orthopedic shoes were fitted with custom-made insoles (33 $\mathrm{ft}(42 \%)$ in patients with unilateral $\mathrm{CN} ; 7 \mathrm{ft}(32 \%)$ in patients with bilateral $\mathrm{CN}$ ). In cases of substantial foot deformity at the reconstruction stage, custom-made orthopedic shoes were built for $39 \mathrm{ft}$ (49\%) of unilaterally affected patients and $12 \mathrm{ft}$ (55\%) of bilaterally affected patients and an orthosis was built for 5 and $3 \mathrm{ft}$, respectively. Following definitive treatment, patients were seen every six to eight weeks, which was extended to six-month follow-up intervals with a positive clinical development.

Table 2 Protected weight-bearing treatment: initial regimen and cast types used

\begin{tabular}{lll}
\hline Cast/Shoe Type & $\begin{array}{l}\text { Unilaterally affected } \\
\text { feet }(n=66) \\
\mathrm{N}(\%)\end{array}$ & $\begin{array}{l}\text { Bilaterally affected } \\
\text { feet }(n=22) \\
\mathrm{N}(\%)\end{array}$ \\
\hline Cast shoe & $3(5)$ & $8(35)$ \\
TCC only & $26(39)$ & $3(14)$ \\
TCC followed by rTCC & $20(30)$ & $5(23)$ \\
TCC followed by & $11(17)$ & $1(5)$ \\
Orthotic/AFO & & \\
$\begin{array}{l}\text { Orthotic (AFO) } \\
\text { Time to shoes, weeks } \\
\text { (mean } \pm \text { SD) }\end{array}$ & $6(9)$ & $5(23)$ \\
\hline TCC Tot Conta Cast, $r C C$ & & $35 \pm 28$
\end{tabular}

TCC Total Contact Cast, rTCC removable Total Contact Cast, AFO rigid Ankle Foot Orthotic

\section{Unprotected weightbearing}

Unprotected weightbearing was defined as orthopedic shoes with custom-made insoles and custom-made orthopedic shoes. Thirteen patients (20\%) with unilateral $\mathrm{CN}$ refused treatment with a cast and were therefore supplied with a non-protected regimen. Of these, orthopedic shoes with custom-made insoles were provided for eight patients, and five patients received a custom-made orthopedic shoe.

Magnetic resonance imaging was used in all patients to detect remaining inflammation six months following non-operative treatment and to rule out deep soft tissue infections. The incidence of ulcer, infection (i.e., positive microbiologic culture of a deep wound biopsy), recurrence of $\mathrm{CN}$ and amputation was recorded in the patient charts during the follow-up visits.

The mean duration of follow-up was 45 months (range 1-208 months).

\section{Statistical analysis}

The start and duration of protected weightbearing, as well as the type of initial treatment, were determined as potential factors influencing the appearance of ulcers and rate of infections, and therefore were considered to be prognostic factors of the disease. All data from patient records were exported into an Excel database (Microsoft Corp, Redmond, WA). For statistical analysis SPSS 17.0 software (SPSS Inc, Chicago, IL) was used. For detection of differences between groups, Chi-square or Fisher's exact test was conducted. Significance level was defined as $P<0.05$.

\section{Results}

\section{Protected weightbearing period}

Patients with unilateral $\mathrm{CN}$ had a shorter time period for protected weightbearing treatment (20 \pm 21 weeks) compared to bilaterally affected patients ( $22 \pm 29$ weeks). In patients with unilateral $\mathrm{CN}$, men had a longer period of protected weightbearing $(24 \pm 22$ weeks) than women (16 \pm 15 weeks), but the difference was not statistically significant $(p=0.88)$.

\section{Ulcer and infection}

Outcomes following a protected weightbearing treatment regimen were compared in unilaterally and bilaterally affected patients. Five of $66 \mathrm{ft}(8 \%)$ of unilaterally affected patients developed new ulcers during the treatment protocol. In contrast, in the bilaterally affected group, 9 of $22 \mathrm{ft}$ (41\%) developed new ulcers during the treatment protocol, indicating a significantly higher incidence of ulceration following a protected weightbearing in bilaterally affected patients compared to unilaterally affected patients $(p=0.004)$ (Table 4$)$. 


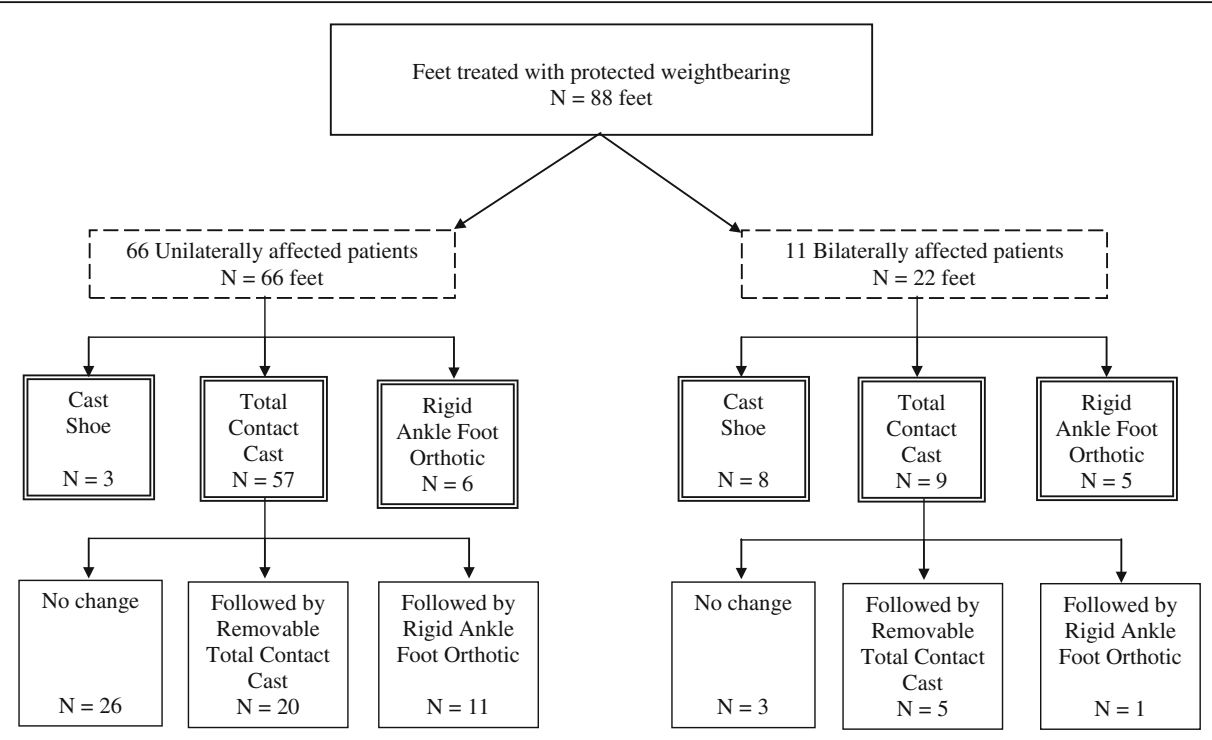

Fig. 2 Flow chart of protected weight-bearing treatment regimen $(n=88 \mathrm{ft})$

In patients with unilateral $\mathrm{CN}$ (Table 5), new ulcerations developed in 5 of $66 \mathrm{ft}(8 \%)$ with a protected weightbearing treatment, compared to 4 of $13 \mathrm{ft}$ (31\%) in patients without a protected weightbearing regimen $(p=0.036)$, indicating a significantly higher incidence of ulceration in an unprotected weightbearing regimen.

Thirteen patients (16\%) in the unilaterally affected group received oral antibiotic treatment for a suggested soft tissue infection with signs of elevated blood infection (CRP $>5 \mathrm{mg} / \mathrm{l})$. Blood tests (CRP levels) were only performed in a clinically suspicious situation, i.e., when a patient presented with redness and warmth of the foot, to discriminate infection from active Charcot arthropathy. Seven of 11 patients (64\%) with bilateral CN were treated with prophylactic oral antibiotics for suspected soft tissue infection in one of their feet (i.e., $7 / 22 \mathrm{ft}$;

Table 3 Protected weight-bearing treatment regimen in bilaterally affected patients

\begin{tabular}{lll}
\hline Patient & Left Foot & Right Foot \\
\hline 1 & Orthotic (AFO) & Orthotic (AFO) \\
2 & Cast shoe & Cast shoe \\
3 & TCC followed by removable TCC & TCC followed by removable TCC \\
4 & TCC & Cast shoe \\
5 & Cast shoe & Orthotic (AFO) \\
6 & Cast shoe & Cast shoe \\
7 & TCC & TCC followed by removable TCC \\
8 & TCC followed by removable TCC & TCC followed by orthotic (AFO) \\
9 & Orthotic (AFO) & Orthotic (AFO) \\
10 & Cast shoe & Cast shoe \\
11 & TCC & TCC followed by removable TCC \\
\hline
\end{tabular}

TCC Total contact cast

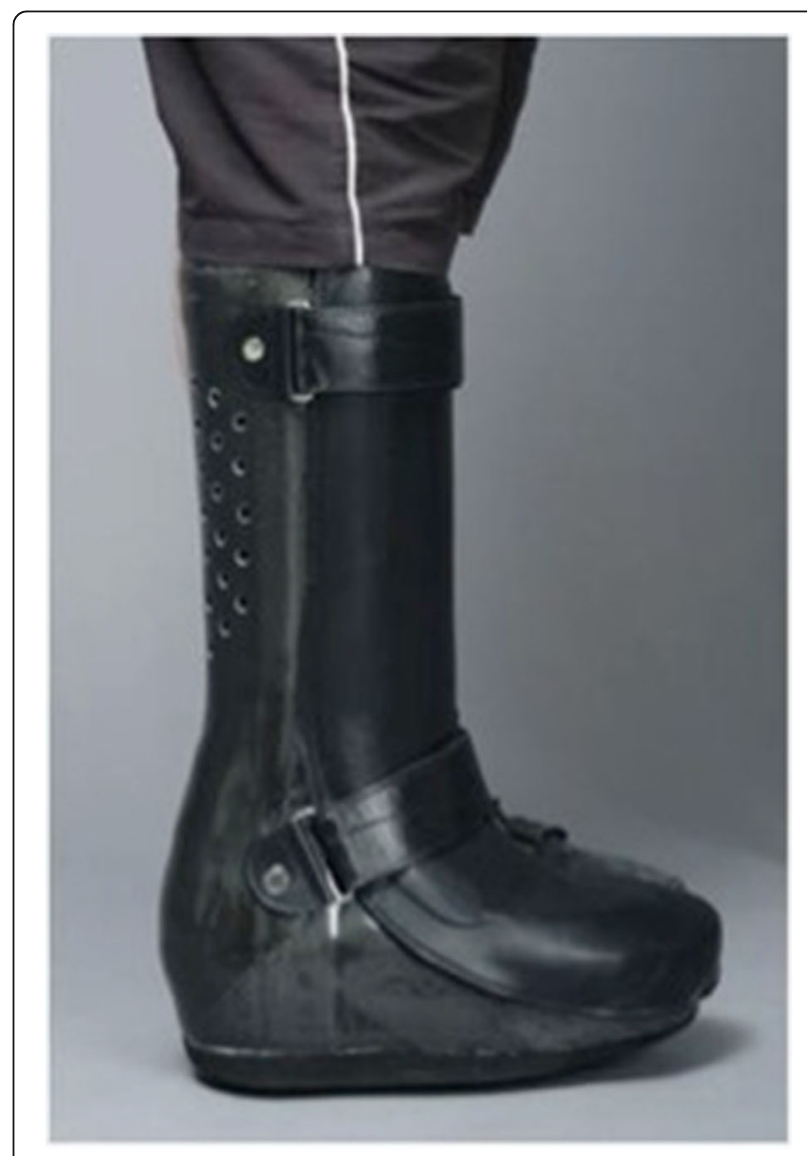

Fig. 3 Example of a rigid ankle-foot orthosis (AFO) 
Table 4 Outcome parameters in $66 \mathrm{ft}$ of patients with unilateral CN compared to $22 \mathrm{ft}$ of 11 patients with bilateral CN, following a protected weightbearing treatment

\begin{tabular}{|c|c|c|c|c|c|}
\hline & \multicolumn{2}{|c|}{$\begin{array}{l}\text { Unilaterally affected } \\
(n=66)\end{array}$} & \multicolumn{2}{|c|}{$\begin{array}{l}\text { Bilaterally affected } \\
(n=22)\end{array}$} & \multirow[t]{2}{*}{$P$} \\
\hline & Baseline & Follow-up & Baseline & Follow-up & \\
\hline Ulceration, n (\%) & $16(24)$ & $21(32)$ & $4(18)$ & $13(59)$ & $.004^{\mathrm{a}}$ \\
\hline - Incidence: & & $5(8 \%)$ & & $9(41 \%)$ & \\
\hline Soft tissue infection, $\mathrm{n}(\%)$ & $2(3)$ & $3(5)$ & $1(5)$ & $2(9)$ & \\
\hline - Incidence & & $1(2 \%)$ & & $1(4 \%)$ & \\
\hline
\end{tabular}

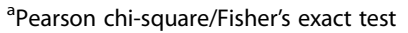

32\%). Empiric oral antibiotic therapy was initiated and, if deep wound biopsies were taken intraoperatively, the patient was either switched to the precise oral or intravenous antibiotic therapy according to culture results and sensitivity testing, or therapy was discontinued in the case of negative culture results.

A total of 60 surgical wound procedures were performed in $50 \mathrm{ft}$ during the follow-up period (Table 6). Wound debridement was performed for superficial ulcerations $(n=47)$. In the case of deep wound infection, deep surgical wound treatment with removal of sequestrum and wound lavage were performed $(n=13)$. Osseous prominences causing recurrent ulcerations were treated by exostosectomy $(n=4)$. All surgical procedures were performed by the head of the department for multidisciplinary treatment of foot ulcerations and foot deformities, or by an experienced consultant. Although bilaterally affected patients demonstrated higher rates (5 $\mathrm{ft}, 23 \%$ ) of deep surgical wound therapy compared to unilaterally affected patients $(8 \mathrm{ft}, 10 \%)$, the rates were not significantly different statistically.

\section{Amputation}

Three toe, 1 forefoot (Lisfranc), and 2 below-the-knee amputations were performed in unilaterally affected patients, and 4 toe amputations were required in bilaterally affected patients (Table 4). There were no statistically significant differences in the rates of amputation or recurrence of $\mathrm{CN}$ for the different treatment modalities.

Table 5 Outcome parameters in unilaterally affected individuals, stratified by protected weightbearing treatment versus unprotected, full weightbearing regimen

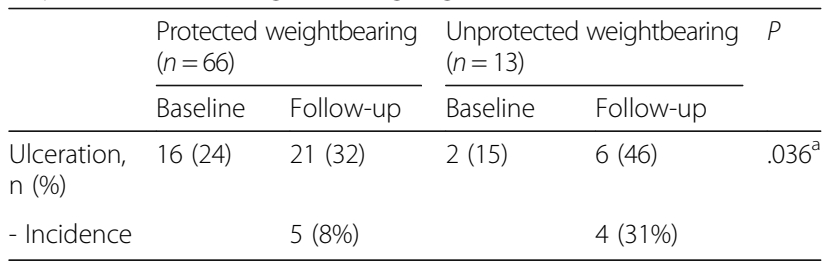

apearson chi-square/Fisher's exact test
Table 6 Surgical procedures performed for wound healing in $79 \mathrm{ft}$ of patients with unilateral CN compared to $22 \mathrm{ft}$ of 11 patients with bilateral CN

\begin{tabular}{lll}
\hline Procedure & $\begin{array}{l}\text { Unilateral CN } \\
(n=79)\end{array}$ & $\begin{array}{l}\text { Bilateral CN } \\
(n=22)\end{array}$ \\
\hline $\begin{array}{l}\text { Wound debridement for } \\
\text { superficial ulceration }\end{array}$ & $33(42 \%)$ & $14(64 \%)$ \\
$\begin{array}{l}\text { Deep surgical wound treatment } \\
\text { (i.e., removal of sequestrum and } \\
\text { wound lavage) }\end{array}$ & $8(10 \%)$ & $5(23 \%)$ \\
$\begin{array}{l}\text { Exostosectomy of osseous prominence } \\
\text { Amputation }\end{array}$ & $3(4 \%)$ & $1(5 \%)$ \\
& 3 toe & 4 toe \\
& 1 forefoot (Lisfranc) \\
& 2 below the knee & \\
& Total: $6(8 \%)$ & Total: $4(18 \%)$ \\
\hline
\end{tabular}

\section{Discussion}

The outcome of non-operative treatment in 90 patients (101 ft) diagnosed with $\mathrm{CN}$ was assessed at a mean follow-up of 48 months (range 1-208 months). The average age of patients in our investigation was 60.7 $( \pm 10.6)$ years, which corresponds to previously published studies [27-29].

Treatment in an orthopedic device, such as a TCC to minimize mechanical forces on the bone, achieve a plantigrade, stable foot and prevent recurrent ulceration, is considered to be an important strategy in acute $\mathrm{CN}$ $[6,24,27,30-34]$. Yet, there is a wide range of recommendations concerning initial treatment. Some authors suggest non-weightbearing treatment during the first months to stop progression of deformity [27, 29, 34, 35]. In particular, they suggest that weightbearing should be prevented during the inflammation stage, to "cool down the foot" because of the risk that the unstable foot will continue to fracture $[10,35]$. Frykberg et al recommended a non-weightbearing period of 8-12 weeks to avoid trauma to the affected foot [34]. Other investigators allowed weightbearing when the foot was placed in a cushioned device [10, 36-38]. De Souza et al showed that protected weightbearing in a TCC does not initiate new foot ulcers in the treatment of a Charcot foot [10]. Weightbearing does not appear to negatively affect the outcome in treatment of acute $\mathrm{CN}$, as long as the foot is protected by a professionally manufactured TCC. Initial treatment in our institution consisted of a custom-made, properly cushioned, rigid plaster boot (TCC) or of a rigid ankle-foot orthosis, with weightbearing allowed as tolerated. This treatment regimen was associated with a lower incidence of ulcerations (8\%) compared to an unprotected weightbearing regimen (31\%) in patients with unilateral $\mathrm{CN}(p=0.036)$. Even overweight patients with stage $1 \mathrm{CN}$ according to Eichenholtz, treated with a TCC that permitted full weightbearing, successfully progressed into therapeutic footwear after an average time 
of 12 weeks [37]. Furthermore, non-weightbearing treatment may have an unfavorable consequence on the contralateral, unaffected limb in patients with $\mathrm{CN}$, due to increased stress [30]. Clohisy et al reported that the time period to affect the contralateral limb is longer (12 months) in patients with weightbearing treatment compared to a weight-off regimen (4.5 months) [39]. Our investigation showed that the incidence of foot ulcers is higher in bilaterally affected patients compared to unilaterally affected individuals $(p=0.004)$. We therefore recommend a weightbearing treatment in a TCC in an acute stage of $\mathrm{CN}$ to prevent, or at least defer, progression of the disease with its complications to the contralateral side.

The alternative to a TCC is a pre-fabricated removable walker cast (i.e. Aircast ${ }^{\circ}$, DJO Global, Cal, USA or Vacoped $^{\circ}$, OPED AG, Cham, Switzerland), which has the advantage of much lower costs compared to a regularly changed custom-made TCC. Use of a TCC for diabetic foot ulcers compared to a removable cast walker or halfshoe showed higher healing percentages and a shorter healing time for the TCC $[2,10,20]$.

Although a $6 \%$ risk for development of pressure ulcers with the TCC has been reported, the rate of permanent sequelae from cast-related injuries is low $(0.25 \%)$, and the TCC was rated as a safe modality for protected weightbearing and immobilization of the neuropathic foot $[13,40]$.

The major disadvantage of a removable, non-custom tailored device is a diminished compliance due to the easy removability of the device by the patient $[41,42]$. This may lead to increased local pressure on the skin and, in combination with insensibility, contains an increased risk of ulceration. Compliance with wearing prescribed footwear is low [42, 43]. Only $28 \%$ of $\mathrm{CN}$ patients wore their removable walker brace full time ( $23.5 \mathrm{~h} /$ day), and non-compliance was shown to lead to a longer bracing period ( $29 \pm 19$ weeks) [43]. An important attribute of the TCC is that it is not easily removable and therefore has the advantage to enhance compliance [41]. It also seems to curtail activity, which reduces the number of stress cycles on vulnerable skin [41].

The protected weightbearing treatment period in a TCC in our investigation was $20 \pm 21$ weeks for unilaterally affected patients and $22 \pm 29$ weeks for bilaterally affected subjects. Our average duration of treatment corresponds to the findings of Armstrong et al with a period of $18.5 \pm$ 10.6 weeks and Christensen et al of $20.1 \pm 3$ weeks [27] However, they reported a re-casting of the unprotected extremity for a mean of 11.2 weeks in cases of exacerbation or recurrence of $\mathrm{CN}$ after reloading, i.e., upon initial cast removal [27, 44]. Bates et al treated 34 patients with a TCC and 12 individuals with a removable cast walker in the presence of contraindications for a TCC for 11 (range: 8 to16.7) months, and 33\% had to extend their treatment period to a total duration of 20 (range, 15 to 21) (Bates M,
Petrova NL, Edmonds ME: How long does it take to progress from cast to shoes in the management of Charcot osteoarthropathy? Diabetes Foot Study Group of the EASD, unpublished) months due to recurrence of inflammation. In our experience, a protected weightbearing regimen should be maintained as long as signs of inflammation such as redness and warmth are present. In the case of inconclusive clinical signs, we recommend performing an MRI to exclude residual inflammatory sites.

In our assessment, we found a shorter period until definitive treatment was initiated (mean 5 months, range 1-65 months), compared to previously published investigations. Game et al reported a duration of treatment to resolution (mobilized in orthotic or normal shoes) of 10 months (range 2-40 months) in a multicenter, webbased observational study of 288 cases in the UK. Armstrong et al suggested a time to footwear of $7 \pm$ 3.6 months in 55 patients with $\mathrm{CN}[44,45]$.

Surgical treatment was performed in cases of chronic ulceration or soft tissue infection to avoid amputation of the limb. In our experience, open surgery on an inflamed $\mathrm{CN}$ foot often ends in disastrous results due to infections, bone resorption, or implant loosening [46]. Therefore, it is essential to find the correct timing for such an intervention.

Nevertheless, there are situations where stability of the foot can only be achieved through operative intervention. In these situations, the circular Ilizarov fixator is an excellent treatment option because of the ability to correct multiplanar deformities [47]. Other investigators provide early reconstructive surgery in patients with advanced instability of the foot. Intervention was associated with a benefit compared to secondary operations after non-operative treatment concerning a stable, ulcerand infection free situation [22]. The goal in $\mathrm{CN}$ treatment is a stable foot either by a multi-level arthrodesis or a firm fibrosis, which can be fitted with a custommade shoe [23, 24]. El-Gafary et al treated 20 patients with $\mathrm{CN}$ at Eichenholtz stage 2 and presence of joint subluxations or deformities with repositioning and stabilization by application of an Ilizarov frame with restricted weightbearing [48]. They reported good clinical outcomes with a time to arthrodesis of 18 weeks (range 15-20 weeks) [48]. However, pin site infections in these situations were frequent (15 of 20 patients).

Our study has limitations. We had no measurements of skin temperature, $\mathrm{HbA1c}$, or body mass index at the onset of disease or during the follow-up period. Also, the potential impact of wounds present at initiation of treatment on the primary outcome of new ulcer incidence is not well understood. Further limitations are the retrospective study design and the lack of precise matching of groups. Although our assessment included one of the largest samples available compared to other studies of $\mathrm{CN}$, evaluation of treatment regimens for this disease would benefit from 
larger, prospective trials with homogenous patient cohorts. Nevertheless, our findings may assist in the decision making and treatment planning for a $\mathrm{CN}$ foot.

\section{Conclusion}

In conclusion, protected weightbearing treatment in a TCC is a valuable option for patients with acute $\mathrm{CN}$, with a significantly lower incidence of ulcerations compared to an unprotected treatment. Larger population studies are recommended to further support this observation.

\section{Abbreviations}

ABI: Ankle-brachial index; AFO: Ankle-foot orthosis; BMl: Body mass index; $\mathrm{CN}$ : Charcot neuropathic arthropathy; CRP: C-reactive protein; HbA1c: Hemoglobin A1C; IL-1B: Interleukin-1B; MRI: Magnetic resonance imaging; NF-kB: Nuclear transcription factor; RANKL: Receptor activator of nuclear factor-kB ligand; rTCC: Removable total contact cast; SD: Standard deviation; TCC: Total contact cast; TNF-a: Tumor necrosis factor-a; UK: United Kingdom

\section{Acknowledgements}

The authors thank Dagmar Gross for assistance with preparation of this manuscript.

\section{Funding}

No funding was obtained for this study.

\section{Availability of data and materials}

All the data supporting our findings are contained within the manuscript

\section{Authors' contributions}

NR carried out the data collection from patient records and radiographs and together with MB, drafted the manuscript. TB helped with drafting the manuscript, gave helpful input during writing of the manuscript, and gave substantial input in revising the manuscript. SW and GO participated in the design of the study, performed the statistical analysis, and helped design al figures and tables. All authors read and approved the final manuscript and all revisions.

\section{Authors' information}

All of the authors are board-certified orthopedic surgeons; additionally, the senior authors BT and BM are specialized in treatment of the diabetic foot.

\section{Competing interests}

Any author listed above, their immediate family, and any research foundation with which they are affiliated, did not receive any financial payments or other benefits from any commercial entity related to the subject of this article.

\section{Consent for publication}

Not required, as there are no identifying data for any individual person.

\section{Ethics approval and consent to participate}

Ethical approval for this study was obtained from the Kantonalen Ethikkommission Zürich, reference \#2016-00271. A copy of the approval letter can be provided upon request. Written informed consent allowing retrospective data analysis was received from all patients enrolled in the study.

\section{Author details}

'Orthopädische Klinik Luzern AG, Hirslanden Klinik St.Anna, Luzern, Switzerland. ${ }^{2}$ Department of Orthopedics, University of Zürich, Balgrist University Hospital, Zürich, Switzerland. ${ }^{3}$ Department of Trauma Surgery, University Hospital of Zürich, Zürich, Switzerland.

Received: 9 January 2016 Accepted: 5 December 2016 Published online: 29 December 2016

\section{References}

1. Miller D, editor. Review of Orthopedics. 2012.

2. Charcot JM. On arthropathies of cerebral or spinal origin. Clin Orthop Relat Res. 1993:296:4-7.

3. Charcot JM. Sur quelques arthropathies qui paraissent dépendre d'une lésion du cerveau ou de la moelle épinière. In: Archive de Physiologie. 1868.

4. Sanders L, Frykberg R. The charcot foot (Pied de charcot), Levin and O'Neal's the diabetic foot: J. H. Bowker and M.A. Pfeifer. 2007.

5. Gupta N, Goel K, Shah P, Misra A. Childhood obesity in developing countries: epidemiology, determinants, and prevention. Endocr Rev. 2012; 33(1):48-70.

6. Armstrong DG, Lavery LA. Monitoring healing of acute Charcot's arthropathy with infrared dermal thermometry. J Rehabil Res Dev. 1997; 34(3):317-21.

7. Herbst $\mathrm{SA}$, Jones $\mathrm{KB}$, Saltzman $\mathrm{CL}$. Pattern of diabetic neuropathic arthropathy associated with the peripheral bone mineral density. J Bone Joint Surg Br. 2004;86(3):378-83.

8. Rogers LC, Frykberg RG, Armstrong DG, Boulton AJ, Edmonds M, Van GH, Hartemann A, Game F, Jeffcoate W, Jirkovska A, et al. The Charcot foot in diabetes. Diabetes Care. 2011;34(9):2123-9.

9. Shapiro SA, Stansberry KB, Hill MA, Meyer MD, McNitt PM, Bhatt BA Vinik Al. Normal blood flow response and vasomotion in the diabetic Charcot foot. J Diabetes Complications. 1998;12(3):147-53.

10. de Souza LJ. Charcot arthropathy and immobilization in a weight-bearing total contact cast. J Bone Joint Surg Am. 2008:90(4):754-9.

11. Jude EB, Boulton AJ. Update on Charcot neuroarthropathy. Curr Diab Rep. 2001;1(3):228-32.

12. Brower AC, Allman RM. Pathogenesis of the neurotrophic joint: neurotraumatic vs. neurovascular. Radiology. 1981;139(2):349-54.

13. Blume PA, Sumpio B, Schmidt B, Donegan R. Charcot neuroarthropathy of the foot and ankle: diagnosis and management strategies. Clin Podiatr Med Surg. 2014:31(1):151-72.

14. Guven MF, Karabiber A, Kaynak G, Ogut T. Conservative and surgical treatment of the chronic Charcot foot and ankle. Diabet Foot Ankle. 2013;4:21177

15. Petrova NL, Foster AV, Edmonds ME. Calcaneal bone mineral density in patients with Charcot neuropathic osteoarthropathy: differences between Type 1 and Type 2 diabetes. Diabet Med. 2005;22(6):756-61.

16. Eichenholtz SNE. Charcot joints. Springfield: Charles C. Thomas.; 1966. p. 3-8.

17. Gazis A, Pound N, Macfarlane R, Treece K, Game F, Jeffcoate W. Mortality in patients with diabetic neuropathic osteoarthropathy (Charcot foot). Diabet Med. 2004;21(11):1243-6.

18. Lee L, Blume PA, Sumpio B. Charcot joint disease in diabetes mellitus. Ann Vasc Surg. 2003;17(5):571-80.

19. Petrova NL, Edmonds ME. Acute Charcot neuro-osteoarthropathy. Diabetes Metab Res Rev. 2016;32 Suppl 1:281-6.

20. La Fontaine J, Lavery L, Jude E. Current concepts of Charcot foot in diabetic patients. Foot. 2016;26:7-14.

21. Schneekloth BJ, Lowery NJ, Wukich DK. Charcot Neuroarthropathy in Patients With Diabetes: An Updated Systematic Review of Surgical Management. J Foot Ankle Surg. 2016:55(3):586-90.

22. Mittlmeier T, Klaue K, Haar P, Beck M. Should one consider primary surgical reconstruction in charcot arthropathy of the feet? Clin Orthop Relat Res. 2010;468(4):1002-11

23. Simon SR, Tejwani SG, Wilson DL, Santner TJ, Denniston NL. Arthrodesis as an early alternative to nonoperative management of charcot arthropathy of the diabetic foot. J Bone Joint Surg Am. 2000;82-A(7):939-50.

24. Pakarinen TK, Laine HJ, Honkonen SE, Peltonen J, Oksala H, Lahtela J. Charcot arthropathy of the diabetic foot. Current concepts and review of 36 cases. Scand J Surg. 2002;91(2):195-201.

25. Baravarian B, Van Gils CC. Arthrodesis of the Charcot foot and ankle. Clin Podiatr Med Surg. 2004;21(2):271-89.

26. Sanders LJ FR. The Charcot Foot. In: The high risk foot in diabetes mellitus. 1st ed. New York: ChurchillLinvingstone; 1991. p. 325-35.

27. Christensen TM, Gade-Rasmussen B, Pedersen LW, Hommel E, Holstein $P E$, Svendsen OL. Duration of off-loading and recurrence rate in Charcot osteo-arthropathy treated with less restrictive regimen with removable walker. J Diabetes Complications. 2012:26(5):430-4.

28. Osterhoff G, Boni T, Berli M. Recurrence of acute Charcot neuropathic osteoarthropathy after conservative treatment. Foot Ankle Int. 2013;34(3): $359-64$. 
29. Fabrin J, Larsen K, Holstein PE. Long-term follow-up in diabetic Charcot feet with spontaneous onset. Diabetes Care. 2000;23(6):796-800.

30. Wukich DK, Sung W. Charcot arthropathy of the foot and ankle: modern concepts and management review. J Diabetes Complications. 2009;23(6):409-26.

31. Chantelau E. The perils of procrastination: effects of early vs. delayed detection and treatment of incipient Charcot fracture. Diabet Med. 2005; 22(12):1707-12.

32. Kimmerle R, Chantelau E. Weight-bearing intensity produces charcot deformity in injured neuropathic feet in diabetes. Exp Clin Endocrinol Diabetes. 2007;115(6):360-4.

33. Sinacore DR. Acute Charcot arthropathy in patients with diabetes mellitus: healing times by foot location. J Diabetes Complications. 1998;12(5):287-93.

34. Frykberg RG, Mendeszoon E. Management of the diabetic Charcot foot. Diabetes Metab Res Rev. 2000;16 Suppl 1:S59-65.

35. Laughlin RT, Calhoun JH, Mader JT. The Diabetic Foot. J Am Acad Orthop Surg. 1995;3(4):218-25.

36. Brodsky JW. Outpatient diagnosis and care of the diabetic foot. Instr Course Lect. 1993;42:121-39.

37. Pinzur MS, Lio T, Posner M. Treatment of Eichenholtz stage I Charcot foot arthropathy with a weightbearing total contact cast. Foot Ankle Int. 2006; 27(5):324-9.

38. Pinzur MS, Shields N, Trepman E, Dawson P, Evans A. Current practice patterns in the treatment of Charcot foot. Foot Ankle Int. 2000;21(11): 916-20.

39. Clohisy DR, Thompson Jr RC. Fractures associated with neuropathic arthropathy in adults who have juvenile-onset diabetes. J Bone Joint Surg Am. 1988;70(8):1192-200.

40. Guyton GP. An analysis of iatrogenic complications from the total contact cast. Foot Ankle Int. 2005:26(11):903-7.

41. Armstrong DG, Nguyen HC, Lavery LA, van Schie CH, Boulton AJ, Harkless LB. Off-loading the diabetic foot wound: a randomized clinical trial. Diabetes Care. 2001:24(6):1019-22.

42. Knowles EA, Boulton AJ. Do people with diabetes wear their prescribed footwear? Diabet Med. 1996:13(12):1064-8.

43. Verity S, Sochocki M, Embil JM, Trepman E. Treatment of Charcot foot and ankle with a prefabricated removable walker brace and custom insole. Foot Ankle Surg. 2008;14(1):26-31.

44. Armstrong DG, Todd WF, Lavery LA, Harkless LB, Bushman TR. The natural history of acute Charcot's arthropathy in a diabetic foot specialty clinic. Diabet Med. 1997;14(5):357-63.

45. Game FL, Catlow R, Jones GR, Edmonds ME, Jude EB, Rayman G, Jeffcoate WJ. Audit of acute Charcot's disease in the UK: the CDUK study. Diabetologia. 2012;55(1):32-5.

46. Bradley LL, Paley D. Charcot neuroarthropathy of the foot and ankle in limb lengthening and reconstruction surgery. In: Limb lengthening and reconstruction surgery. London: Informa Healthcare; 2007.

47. Yousry AH, Abdalhady AM. Management of diabetic neuropathic ankle arthropathy by arthrodesis using an llizarov frame. Acta Orthop Belg. 2010; 76(6):821-6.

48. El-Gafary KA, Mostafa KM, Al-Adly WY. The management of Charcot joint disease affecting the ankle and foot by arthrodesis controlled by an llizarov frame: early results. J Bone Joint Surg Br. 2009;91(10):1322-5.

\section{Submit your next manuscript to BioMed Central and we will help you at every step:}

- We accept pre-submission inquiries

- Our selector tool helps you to find the most relevant journal

- We provide round the clock customer support

- Convenient online submission

- Thorough peer review

- Inclusion in PubMed and all major indexing services

- Maximum visibility for your research

Submit your manuscript at www.biomedcentral.com/submit
Biomed Central 